\title{
CD3+/CD19+ Cell-depleted Unrelated or Partially Matched Donor-derived Allogeneic Peripheral Blood Stem Cells
}

National Cancer Institute

\section{Source}

National Cancer Institute. CD3+/CD19+ Cell-depleted Unrelated or Partially Matched

Donor-derived Allogeneic Peripheral Blood Stem Cells. NCI Thesaurus. Code C162765.

A preparation of allogeneic peripheral blood stem cells (PBSCs) from an unrelated or partially matched related donor that have been selectively depleted of CD3-positive (CD3+) T-cells and CD19-positive (CD19+) B-cells via leukapheresis with potential immune reconstituting activity. The CD3+/CD19+ cell-depleted PBSCs are used for allogeneic hematopoietic cell transplantation (HCT) and may allow for rapid and sustained eng raftment, immune reconstitution, and may prevent or reduce graft-versus-host disease (GvHD) and Epstein-Barr virus (EBV)-driven post-transplant lymphoproliferative disorders. 